\title{
Influence of Socio-Cultural Practices on Girl Child Participation in Secondary Schools in Garowe, Puntland
}

\author{
Abdigafar Mohamoud Mohamed \\ Master of Science in Development Studies at the Jomo Kenyatta University of Agriculture and Technology \\ Dr. Hellen K. Mberia \\ Dean of School of Communication and Development Studies at the Jomo Kenyatta University of Agriculture \& \\ Technology - JKUAT Nairobi - Kenya \\ Dr. Willy Muturi \\ Senior Lecturer at the Jomo Kenyatta University of Agriculture \& Technology - JKUAT Nairobi - Kenya
}

\begin{abstract}
Female education, especially at secondary school level, is increasingly being realized to provide immense social and economic benefits for the developing countries. However, the participation of girls in education is more often constrained in these countries. As a result, gender gap persists in education despite the research evidence that girls' formal education is the key determinant of women's involvement in development for the above nations. In Somalia, especially semi-autonomies Puntland states have articulated its commitment to providing Primary Education for all its school age children and put forward efforts to ease access, retain and performance of girls at the secondary schools. In spite of this commitment, low female participation in education remains a drawback to realizing an ideal equality and universality of primary/secondary education. Garowe town is still lagging behind as far as girls' participation in secondary education is concerned. Therefore the objective of the study is to examine the socio-cultural influence on girl child participation in education including the parent's attitude on girl child education, religious beliefs, gender preferences and female role model effects. The study adopted descriptive survey research design utilizing qualitative approaches. The population target by the study included girl students, parents, teachers, principals, and religious leaders Garowe District, as well as the District Education Officer. The study used questionnaires and observation checklist as research tools. The study concluded that some of the local communities contribute to girls not being in school because girls are booked for early marriage, some underestimate the result of the girl education and some parents use their daughters as a source of wealth through getting dowry. Girls look after young siblings at home and do domestic chores while boys go to school. Fellow pupils especially girls themselves feel culturally out of place as they do not want to compete with boys particularly in a mixed gender schools. The limitation of the study was data gathered such as comments from other respondents, anxiety, stress, motivation on the part of the respondents while on the process of answering the questionnaires.
\end{abstract}

\subsection{Background}

\section{INTRODUCTION}

Education is the best legacy a nation can give to her citizens especially the youth. This is because the development of any nation or community depends largely on the quality of education of such nation. It is generally believed that the basis of any true development must commence with the development of human resources. Access to education by women is considered a significant indicator for the progress of a society. According to S. Murphy (2009), the education of women in a society determines its social, financial, natural, physical and human capitals, and contributes to its growth and development. Education is a significant factor influencing the socio-economic and health conditions of the family and for determining gender relations in society. Moreover, as Nobel Laureate Amartya Sen (1989) stresses, the education of women strengthens their position in the family and community and thereby produces multiple benefits. One of the key objectives of the World Education forum on Education for all adopted by the World Summit for Children in 1990 is universalizing access and promoting equity in the area of education. This Forum identified provision of access, the improvement of quality education for both girls and women and remove obstacles that hampers their active participation and all gender stereotyping in education as an urgent priority area for development intervention.

According to Ocho (2005) Education is the process through which individuals are made functional members of their society. Education is a human right that should be accorded to all human beings solely because of being human. Many International Human Right institutions advocates for education as a fundamental human right. These include the 1948 Universal Declaration on Human Rights, the 1966 International Covenant of Economic, Social and Cultural Rights and the 1981 Africa Charter on Human and People's Right. This is why there has been a lot of emphasis particularly in recent times for all citizens of the world to have access to Basic 
Influence of Socio-Cultural Practices on Girl Child Participation in Secondary Schools in Garowe,

Education. According to a survey, done by the UNESCO (2013) in African countries, girls seem to be doing better at key competency tests. Girls participate better in higher education than boys especially in secondary schools. Even though there has been much reform, in rural areas social and cultural patterns, combined with the relatively poor quality of schooling, place girls and their education and development in a disadvantaged position. Girls and their education are also disproportionately affected by cultural and economic issues like domestic duties, transport, and school fees Brock, C. (1991). All these issues mentioned above have consequently resulted in high school dropout rates for Eastern and Southern African girls.

\subsection{Benefits of Girl Education}

Education is one of the major instruments of social change and it is the force, which brings changes in the traditional out look of the people, and it develops insight for judging things in their context. It is visualized that more the percentage of educated people more will be the rate of development. Education of a girl is like educating a family while educating a boy is merely educating a person. The importance of female education in a society and its spreading to all section of the life is well appreciated and documented to solve existing and emerging problems of the society.

\subsection{Girl Education in Somalia}

The limited participation of girls in the Somalia education system is linked to the historical development of education in the country. Education in its traditional form has a long history in Somalia. Originally, the educational system was predominantly religion-oriented to serve the manpower needs of the Quranic Madrasas, the mosque and the state (Abdi 1998). The Puntland Government has shown a serious commitment on improving the quality of Education at all as indicated by the launching of ESSP I II in 2015. The previous strategy has shown significant achievements in improving the teaching and learning environment for Secondary Education. There were tremendous efforts in the construction of classrooms, teacher offices and houses, toilets facilities and the general rehabilitation of some of the school buildings. But this has never been viewed on gender equality issues specially the sociocultural effects.

It has been observed that, the general accessibility, retention and performances of girl's enrollment in national trends are poor. For example, as shown below the enrollment trends Puntland Education Statistics Yearbook $2014 / 15$

Enrollment Trends
\begin{tabular}{|l|r|r|r|r|r|r|r|r|r|}
\hline \multirow{3}{*}{$\begin{array}{l}\text { School } \\
\text { Type }\end{array}$} & \multicolumn{3}{|c|}{$2012 / 13$} & \multicolumn{3}{c|}{ 2012/14 } & \multicolumn{3}{|c|}{$2014 / 15$} \\
\hline & Male & Female & Total & Male & Female & Total & Male & Female & Total \\
\hline Secondary & 7,948 & 4,862 & 12,810 & 11,843 & 5,953 & 17,796 & 13,193 & 7,055 & 20,248 \\
\hline
\end{tabular}

Source: EMIS/MoEHE Puntland 2015

\subsection{Statement of the problem}

Education is considered to be a basic human right and a basic need for all. This is because of the crucial role it plays in the human development. Girl-child education is recognized as one of the critical pathways to promote social and economic development. Disparities among the gender have been identified as major in education enrollment and performance (UNESCO 2013). The girl child education has been identified as one of the major route to achieve gender equity and contribute nationwide increase of Human Development Index. Girl child right to education has been ignored and remains unrealized for many people. Secondary enrolment in SubSaharan Africa (SSA) continues to be the lowest in the world. Of approximately 104 million secondary schoolage children in the region, only one in four (25\%) were enrolled in secondary school in 2006 (UNESCO, 2008). Of those, there were 83 girls for every 100 boys (ibid, 2008).

Although the government has made progress in improving girls' education, the National Secondary school Gross Enrolment Ratio (GER) of Somali girls now standing at 20.2\% and still amongst the lowest recorded in the world (Abdullahi, 2013). Despite the numerous campaigns made by the Puntland government and other stakeholders such as UN and NGOs in the country, female enrollment at Garowe town secondary schools, Nugal region is very low as many girls do not go to school or drop out before reaching the education cycle. Generally, the completion of girls in secondary education in of Puntland region seems challenging and the gap is significant in Garowe, Nugal region as enrollment barriers and drop-out rates of girls in the region remain high throughout secondary education (GWG/MoEHE 2015). This study is therefore aim at finding out why this area despite of efforts by the governments and other stake holders' investment in education is still lagging behind in terms of girls' school enrolment and performance. That is why the researcher is attempting to 
establish the sociocultural factors influencing the girls' retention rates in secondary schools, particularly, influence son the parent attitude, religious belief, gender preference, and role model.

\subsection{Objectives}

The general objective of the study was to examine the influence of socio-cultural practices on girl child participation in education in Puntland State.

\subsubsection{Specific Objectives}

The specific objectives of this study were;

1. To determine the influence parent's attitudes on girl-child participation in Secondary School in Garowe Town.

2. To examine the influences of religious belief on girl child participation in Secondary School in Garowe Town.

3. To determine the influence of gender preference on girl child participation in Secondary School in Garowe Town

4. To determine the influences of female role model on girl child participation in Secondary School in Garowe Town

\subsection{Human Capital Theory}

\section{LITERATURE REVIEW}

Theories provides explanation, guidance and prediction on the research study and influence of independence variables to the dependent variables, by providing strong base with supporting theory. However the study used Theory of Human Capital and Socio-Cultural Theories to examine the factors that influence the sociocultural practices on girl child participation in secondary school in Garowe town.

This study is guided by the theory of human capital as advanced by Schultz (1971). Theodore Schultz defined human capital as a measure of the economic value of an employee's skill set. This measure builds on the basic production input of labor measure where all labor is thought to be equal. The concept of human capital recognizes that not all labor is equal and that the quality of employees can be improved by investing in them. The education, experience and abilities of an employee have an economic value for employers and for the economy as a whole (Schultz, 1971).

The theory postulates that an individual bears the costs (direct costs such as fees paid and indirect costs such as opportunity cost on student time) of education because s/he expect that this investment will create a future stream of benefits to $\mathrm{h} / \mathrm{her}$ (higher productivity and thus higher wages). There's a significant bulk of literature and research to underscore this fact: For instance, Psacharopoulos and Patrinos study (2004) conclude that educational quality, (measured by cognitive skills) has a strong impact on individual earnings, moreover educational quality has a strong and robust influence on economic growth with "truly causal relationships". Ersado (2011) considered how differences in the distribution of incomes in males and females were affected by the distribution of skill and concluded that "the bulk of the variation in earnings dispersion was generated by skill dispersion between sexes. The significance of human capital theory to this research on girls' achievement is that the girls will acquire knowledge and skills from the secondary schools after graduation which they can use for productivity

\subsection{Socio-Cultural Theories}

Socio-cultural theory is the second theory that framed this study. This theory embraces the elements of social Constructivism Theory, Social learning Theory and Cognitive learning Theories. Such theorists understand the processes by which children learn gender appropriate behavior in the same way children learn in general. Other theories include Gender Schema theory which focuses to explain gender development and differentiation and psychoanalytic theory for example, emphasizes the unconscious processes involved in developing gender identity. Likewise, social Constructivism asserts that gender is best understood through a cultural perspective (Kukla, 2000 \& Vygotsky, 1978).

Social constructivism is one of the three main schools of thought in the constructivist theory of education. Lev Vygostsky, a Russian psychologist and philosopher in $1930^{\mathrm{ee}} \mathrm{s}$, is most associated with social constructivism theory and has been supported by many educational social constructivism theorists like Kenneth Gergen and John Dewey. He emphasizes the influence of cultural and social context in learning and supports a discovery model of learning. The basic principle behind social constructivism is that the knowledge is constructed through social interaction, and is the result of social processes Gergen,(1995).

In the model of social of social-cultural perspective, reality is formed by a social consensus and is based on social interaction. For the knowledge to be truthful, it must match the social consensus and be functional (Bandura, 1977) school learning and female academic performance in particular, is built on what the 
Influence of Socio-Cultural Practices on Girl Child Participation in Secondary Schools in Garowe,

community knows based on their cultural expectations of women. This theory will help to explain how gender gap occurs in education. The perception of teachers, students, parents and religious leaders on the issues of the cultural values of smart girls; and the general perception of community ex expectations of girls lead to female performance or underperformance.

\subsection{Parent Attitude and Perception}

Family involvement is the strongest predictor of child educational outcomes. This dimension associated significantly with children's motivation to learn, attention, task persistence, receptive vocabulary skills, and low conduct problems. Family involvement in education has been identified as a beneficial factor in young children's learning (National Research Council [NRC], 2001; U.S. Department of Education, 2000). Mainly, family has responsibility to socialize children for making them productive members of society. The more the parents involve in the process of imparting education to their children, the more the children might excel in their academic career and to become the productive and responsible members of society. According to Desimone (1999) and Van der Warf, Creamers and Guldemont (2001), parental involvement is not only necessary but it is also one of the most cost-effective means of improving quality in education.

Higher levels of parent involvement in their children's educational experiences at home (e.g., supervision and monitoring, daily conversations about school) have been associated with children's higher achievement scores in reading and writing, as well as higher report card grades (Epstein, 1991; Griffith, 1996; Sui-Chu \& Willms, 1996; Keith et al., 1998). Parental attitude and support has a great deal of influence on girls' participation and level of success attained in education. Parents and community attitudes are mainly influenced by traditional beliefs regarding the ideal roles of women and girls in society. Traditionally, the only roles available to women were those of wives and mothers. Women were thus seen as nurturers and mainly as providing support for men who worked to provide for the family. Being physically weaker, women were therefore also perceived as being less capable and requiring the protection and guidance of men. These attitudes have prevailed even in current times when socio-economic changes have resulted in changes to roles women are now expected to undertake. Socio-economic changes have made education necessary, not just for the purposes of providing income earning opportunities, but also for the potential to contribute to the improvement in the standards of living of individuals, families and communities. The attitude of the parents signifies that the supporting nature of family in their children's education. The parental attitude can be negative or positive. The negative attitude of the parents regarding education and schooling can prevent their children from getting education. With less parental support in school work, low level of motivation and poor self-esteem of children can result Positive attitude of the parents can be beneficial to their children in many cases and can be reflected in improvement in class performance, creating interest among children to learn, and higher achievement scores in reading and writing (Parker et al., 1997).

Parents may have poor knowledge of the benefits of educating their daughters. According to King (1991) parents who are not aware of the benefit of education are intergenerational, and in fact accumulate over time. Or families may not appreciate the benefits of education. A country where the "suitableness" of more highly educated women to be good wives is held in doubt. The same study found that highly educated women's possibilities for marriage become limited. Parents find it hard to understand the benefits of education when curricula are irrelevant to the mother-wife role or contradict the value they want to teach their children (King 1991). These cultural considerations vary widely among and within countries and it differ in parental education level and hence affect females' school enrollment. Parental education and cultural factors may also cause families to differ in the priority they place on schooling children and their perceptions of the appropriateness of child labor (World Bank 2004). Parents' education has an important influence on gender differences in education. Studies indicate that the more education parents have, the more they value formal education for their daughters. Parents' education measures the degree to which parents are open to influences other than tradition. Also parents' education servers as a limited measure of family income or wealth when more direct measures are not available (Hill and King 1993).Even though many scholars agree on the opinion that parents' literacy affect females' schooling, the educational background of parents especially mothers has a bearing on the academic achievement and participation of female students (Genet 1998). According to Hill and King (1993), and Hyde (1993), African women bear large part of the burden of educating their children. Their own level of education and command of resources are important factors in their ability to keep their children in school. The studies showed that households headed by educated females are more likely to send girls as well as boys to school and to keep them there longer than households headed by uneducated females or by males. This suggests that mother's education has key influence on the participation of daughters in schooling. Perhaps, the mothers also serve as role models to their daughter.

Somalia has a number of examples of cultural practices that compromise girls' access to education and therefore their participation in complete cycle of education especially in Puntland. These practices underline the fact that in such cultures and indeed in many areas in Africa, girls like in traditional times continue to be 
considered the property of their families, with little or no say in their future. Culture describes domestic roles for girls. Domestic chores such as cooking and cleaning the house which take up alot of time are assigned to girls. Girls therefore have little time for study or home work. According to Ray, R. \& G. Lancaster (2003) households chores affects school work more particularly the education of girls who are overwhelmed by a burden of work at home and at school.. In other areas of Puntland, girls and women cross over into neighboring towns and villages to carry out trading which is often a lucrative activity. Their success has been found to lure other school girls to try this business, leading to school dropout.

Several studies carried out focused on socio cultural aspect of obstructive to education for girls and two neighboring countries are selected in order to compare the culture. Pakistan is one of the country which still have gender disparity in education even seems to have been increasing since EFA declaration. Iran has almost achieved to certain point and has less gender disparities in education. Both countries have similar culture for girls and women that they must not appear carelessly in the public sphere. Survey was conducted in Pakistan and Iran for parents who has school aged children in order to find out education vector in line with basic culture (A. Keiko 2012). The parents' attitude against girls were basically same in both countries but attitude to value of education was different even parents themselves didn't have educational background.

\subsection{Female Role Model}

Female teachers are often recognized as a key factor for encouraging girls' enrollment and for addressing quality and retention challenges. Policy and research reports suggest increasing the number of women in the teaching profession as a strategy for getting girls in school and retaining them World Bank (2001). As the numbers of women teachers grow, so do girls' enrollment in school increase. Parents are more likely to send their daughters to school if there is a female teacher Rihani, (2006).

According to Juma (1994), girls have low academic aspirations among ethnic groups where girls had internalized sex-role expectation for women. Many female pupils have internalized self-images of academic inferiority conveyed by parents and teachers. Sifuna (2005) observe that many girls are not ambitious or interested in school because of societal, including parents and teachers expectations that their primary roles are to be wives and mothers. They are socialized to believe that formal education is not required to fulfil these roles. According to Sifuna (2005), patriarchal attitudes which assigned inferior status and roles to women played a major role in societal attitude that education is less important for females in most African countries. On the part of girls themselves, internalization of sex roles expectations reduced girls se self-esteem and academic ambition.

Tiruneh and Petros (2014) conducted a study on factors affecting female students' academic performance at higher education, findings of the study reveals that girls' expectations of their school performance and career prospects play significant roles in their persistence at school. Female students selfperception on their academic performance is lower and they perceive themselves like they are academically weak and they believe that we can't. Female teachers also affect retention rates, sometimes for both boys and girls. Generally, schools with more gender-balanced work forces tend to positively affect a girl's ability to join and stay in school (UIS, 2010). Higher proportions of female teachers in Bangladesh led to higher enrollment and lower rate of failure for both boys and girls at primary level; moreover, at the secondary level the effects of female teachers are more pronounced. Dropout rates for girls were even lower if their female teachers had college degrees. Somali people believe that girls should not be taught by male teachers, however, female teachers are not available or few are in schools in Somali society which is the foremost reason for the low rate of female education.

Nur (2010) indicated that there is lack of role models for girls in schools of Somalia because most of the teachers and the administrative personnel are male. For example some reports show that only $7 \%$ of teachers at primary level are female and only $1 \%$ of teachers at the secondary level. Discussions with girls in schools also indicated that they found it impossible to ask male teachers for permission to go to latrines. This practice does not only reduce the attention span and concentration, but also contributes to absenteeism and consequently poor performance of female students. In the classroom, there is little or no encouragement of female students from teachers.

Kimondo (2013) reveals that the availability of role models and mentors was also one of the factors that contribute to poor performance in girls. Most of the schools were dominated by male teachers. The students lacked role models in schools and even in the society leading to low grades. In His Study a significant number of girls said that the parents are not good role models because they are lazy, they abuse alcohol and other substance they do not have time for mentorship as they are too busy looking for money. The teachers were not good role models because they were lazy, rude, gossipers, do not take time to inspire and motivate, did not attend lectures on time and that they were under qualified to teach thus skipped most difficult topics. In regards to sources of inspiration for students the teachers. Empirical evidence illustrates the importance of female teachers for promoting girls' education. Recruiting and training individuals to serve as educators presents numerous challenges. Africa - noted earlier - is a continent with growing and highly diverse needs, especially 
Influence of Socio-Cultural Practices on Girl Child Participation in Secondary Schools in Garowe,

when considering the barriers to girls' education. It presents researchers and practitioners with a unique set of challenges. This report now focuses on the challenges of staffing teaching positions in African countries, followed by considerations specific to female teachers on the continent.

\subsection{Empirical Literature Review}

The research of this kind has been done by different researchers in order to look to the issue of girlchild education and its evaluation. Most of the related resources have their research questions, basic assumption, and hypothesis different in one way or the other, this research work. Due to the large difference in the enrolment between boys and girls in Africa, there are far more girls than boys who out of the school or denied to access and retain the schools. Education is main element of economic growth because it is directly concerned with employability, entrepreneurship, women empowerment and productivity. Because it make possible the youth with enhanced ability, creative and systematically skilled to race with the fast altering global inclination. It is not difficult to find out the main reasons of dropout, there is no single factor causing dropout. But a number of factor are involved which directed it as a procedure (Hunt, 2008). African scholars and researchers have also supported the important role of women's education, especially at the university level. The Forum for African Women Educationalists (FAWE), based in Nairobi, has conducted a number of these studies. Possibly the most comprehensive recent work on women's higher education in Africa was conducted in Uganda by Kwesiga (2002). She focuses on the role of familial influence, parental attitudes, socio-economic status, and gender differentiated roles and how these issues impact women's persistence in education.

Research indicates that the importance household members place on education is an important factor in whether children gain access to schooling and for how long, but there is less research on how this may attribute to denial of accessibility and dropping out. Research also indicates that the educational level of parent is particularly influential in determining whether and for how long children access schooling and which age to start. Most of Muslim countries like Somalia parents prefer to send both their sons and daughter to Madaras equally before the age of 7 years, while this is compulsory according to Islam religion. Ersado (2013) talks of 'the widely accepted notion that parental education is the most consistent determinant of child education (and employment decisions)'. Higher parental/household head level of education is associated with increased access to education, higher attendance rates and lower dropout rates (Jamie, 2011). A number of reasons are put forward for the link between parental education and retention in school. Some researchers indicate that noneducated parents cannot provide the support or often do not appreciate the benefits of schooling (Brown \& Park, 2011). They posit that parents' level of education instills passion for education in the parents which in turn assists in retaining the female.

\section{METHODOLOGY}

This study adopted the descriptive survey design. This design is ideal for gathering information regarding people's behavior, attitudes, feelings and opinions about girl child educational issues (Kombo \& Tromp, 2006). Also according to MacKenzie (2013) research design is a framework project, it detailed the procedures necessary for obtaining the information needed to structure or solve business research problems. The research design was concern and involve all girl students, parents, head teachers, teachers and also most importantly the religious leaders in Garowe town. It is a survey research which involved collection of data from the field in other to make generalization. This is also stated by Puhan. G. (2010) who says that survey collects data about variables or subjects as they are found in a social system or society. The population of the study were 3,256 consisted all the secondary schools in Garowe town, the school principal, teachers, CEC/parent members, teachers, religious leaders, central and district level staff members for secondary schools in Garowe town. The study employed both stratified and simple random sampling techniques. Stratified sampling in terms of gender aspects was used at the first stage to ensure representation of both gender groups. . Yamane (2007) formula was used to get the actual sample size.

\section{CONCLUSION}

The conclusions arising from the findings of the research that sought to find out the influence of sociocultural practices on girl child participation in secondary education in Puntland were summarized below. The pastoral community of Puntland give more preference to Quranic schools than the secular schools thus there is low enrollment at secondary level education. The study revealed that traditional sex role stereotypes and expectations by the community disadvantage girls because they are forced to perform most domestic chores than boys leaving them exhausted and with no time for doing their studies and homework. All the four influence were found to significantly impact on the accessibility and retention rates. The research found out that religious beliefs, and cultural beliefs and dress code affected girl's access to and participation in both early stage and transition to upper grade (secondary school) education in Puntland. 
Influence of Socio-Cultural Practices on Girl Child Participation in Secondary Schools in Garowe,

\section{RECOMMENDATION}

The findings reported in this study have a number of implications for the policy makers, head teachers, teachers, parents, sheikhs and other stakeholders in the education sector. Hence the following recommendations may help improve girl child education. Based on the study findings and reviewed literatures, this study made the following recommendations; the parents should be sensitized on the importance of girls' education so as to understand their role and involvement in their girl's child education. Every school should be mandated to organize general parent meeting to enable the parents to meet teachers and discuss problem affecting their girl's education. These parents should be advised on the need to motivate and encourage their child girls to remain in school. Since then, the government should strengthen the basic adult literacy programmes Puntland and implement compulsory of Universal Primary education. These programmes could assist both parents and religious leaders to recognize the value of girls formal education and in turn discard the out dated cultural practices and misinterpreted Islamic beliefs that hamper government should strengthen the basic adult literacy programmes Puntland and implement compulsory of Universal Primary education. These programmes could assist both parents and religious leaders to recognize the value of girl's formal education and in turn discard the out dated cultural practices and misinterpreted Islamic beliefs that hamper. The parents should treat their children/wards equally irrespective of their gender. That parents should be more sensitized on issues regarding to gender sensitivity in order to curb discrimination among secondary school students. That parents should play their roles with equity is dealing with their wards because discrimination starts from the family. More bursaries to poor secondary school girls: The government should consider allocating more bursaries to secondary school girls who are unable to offset their tuition fees.

\section{REFERENCES}

[1] Abdi, A. 1998. Economic liberalization and women's education: Prospects for post-apartheid South Africa. McGill Journal of Education 33: 71-84.

[2] Abdullahi, K. (2010). Understanding Garowe and its Dynamics. Garowe: East African

[3] Bandura, A. (1977). Social learning theory. Englewood Cliffs, NJ: Prentice Hall.

[4] Brock, C. (1991). Factors Affecting Female Participation in Education in six developing countries. London: ODA.

[5] Desimone, L. (1999). Linking par mone, L. (1999). Linking parent involvement with student achievement: Do race and income matter? Journal of Educational Research,

[6] Ersado, J. (2011). Putting the Girls First in Education. Kathmandu: Killian Books.

[7] Hunt, F. (2007) Schooling Citizens: A study of policy in practice in South Africa. Unpublished DPhil thesis. Brighton: University of Sussex.

[8] Juma MN (1994). "Determination of Female Participation in Primary Education: A Survey of Kwale and Taita Taveta Districts.'Unpublished Doctor of Philosophy Thesis, Kenyatta University, Nairobi

[9] Kimondo, M. W. (2013). Factors Influencing the Academic Performance of Girls in Secondary Schools: A Case of Embakasi District, Nairobi County, Kenya.

[10] King, E and Hill S. (2007). Women's Education in Developing Countries: Barriers, Benefits and policies. Baltimore: D-John Hopkins University Press.

[11] Kombo, D.K., \& Tromp, L.A. (2006). Proposal and thesis writing. Nairobi: Paulines Publications Africa

[12] Kwesiga, C.J. (2002). Women's access to higher education in Africa: Uganda's experience. Kampala: Fountain publishers Ltd.

[13] Mackenzie, N. (2013). Research dilemmas: Paradigms, methods and methodology. Issues In

[14] Murphy, S., Belmonte, W., and Nelson, J. (2009). Investing in Girls' Education: An Opportunity for Corporate Leadership. Harvard Kennedy School Corporate Social Responsibility Initiative.

[15] Nur, Z. (2010). Forum for African Women Educationalists, Somalia Chapter. Report is prepared for $U P R$.

[16] Ocho, L.O. (2005). Issues and concerns in education and life. Enugu: Institute of Development Studies, University of Nigeria.

[17] Psacharopoulos, G. (1973) Returns to Education: An International Comparison (Amsterdam, Elsevier)

[18] Puhan, G. (2010). A comparison of chained linear and post stratification linear equating under different testing conditions. Journal of Educational Measurement, 47, 54-75.

[19] Ray, R. \& G. Lancaster (2003). Does Child Labour Affect School Attendance and School Performance? Multi Country Evidence on SIMPOC Data. Unpublished Report. ILO/IPEC.

[20] Schultz, T. W. (1971). Investment in Human Capital. New York: Free Press.

[21] Sen, A. (2000) Development as Freedom. New Delhi: Oxford University Press.

[22] Sifuna, D.N. (2005). Increasing Access and participation of pastoralist communities in the primary Education in Kenya. Review of Education 51.499-516. 
Influence of Socio-Cultural Practices on Girl Child Participation in Secondary Schools in Garowe,

[23] Tiruneh and Petros (2014) Factors affecting female students' academic performance at higher education: The case of Bahir Dar University, Ethiopia. African Educational Research Journal Vol. 2(4), pp. 161-166.

[24] Vygotsky, L. S. (1997). The collected works of L. S. Vygotsky, Vol. 4: The history of the development of higher mental functions (R. W. Rieber, Vol. Ed; M. J. Hall, Trans.). New York: Plenum Press.

[25] World Bank. 2001. Engendering Development through Gender Equality in Rights, Resources, and Voice. World Bank Policy Research Report. New York: Oxford University Press.

[26] Yamane, Taro. (1967). Statistics: An Introductory Analysis, 2nd Ed. New York: Harper and Row. 